\title{
On effects of Foreign Direct Investment on Economic Growth
}

\author{
Xinglong Xie \& Hongqi Wang \\ School of Business Administration, Xi'an University of Technology, P.R. China, 710048 \\ E-mail:long86886@yahoo.com.cn
}

The paper is sponsored by the National Natural Science Foundation of China NO.0673080 and the University Doctor Program NO.107-210611.99398

\begin{abstract}
Through the individual fixed effects model, the article makes the empirical study of 23 developing host countries, concluding that FDI weakly influences on the economic expansion rate directly and indirectly, the interaction term of FDI with regime affects the growth rate significantly and what is more, FDI's interaction with regime contributes to the economic increase extensively through crowding in domestic investment. The regime in host countries imposes the positive effect on economic development mainly by means of two channels: one is crowding in FDI inflows into the host countries and the other one is to promote the increasing in domestic investment strongly. Therefore, good institutes are the critical determinant of the beneficial effects of FDI reaped in host countries. Consequently, developing governments should design the quality institute and make the innovation in regime for obtaining benefit from the technological spillovers of FDI so as to enhance their economic growth persistently.
\end{abstract}

Keywords: Regime; Foreign Direct Investment; Individual Entity Fixed Effects Regression Model

\section{Introduction}

Foreign direct investment has been on the rise rapidly in the world, particularly developing transitional countries since 1980s.During the period of 28 years from 1980 to 2007 its annual growth rate reached $121 \%$ globally and stood at $237 \%$ in developing countries. By 2007 FDI stocks had been million USD 4246739 in developing economies, accounting for $28.9 \%$ of the global amount. Developing governments have been improving their investment climate, formulate policies and measures in favor of FDI for the sake of attracting more FDI into their homes.

FDI is regarded as the incubator of capital stocks, special knowledge and technology, an important channel of transferring technology. Compared with domestic investment, FDI is featured by spilling its technology, expertise, management skills, new modes of business and marketing ideas to the local enterprises for the host countries into which it moves and this can promote the host countries' technological capability and economic sustainable expansion. They absorb FDI's technology, management methods, marketing philosophy and commercial models to actualize the optimizing of the resources disposition, shift useable production resources into the sectors which have comparative advantages and turn potential comparative advantages into real competitive ones, accelerating national economic expansion and bolstering the economic growth in the long run, and finally takes the way of endogenous development in their national economy.

However, the empirical evidence shows the difference regarding the relationship between FDI and economic growth. To sum up, the researches at the industry level show spillover effects more than at the enterprises level; compared with other types of data, panel data leads to significant effects ; given the same level and data types, results form the researches of advanced countries propose more positive effects from FDI than ones from developing counterparts.

In recent years a large number of researchers take into consideration more production elements for exploring the relationship between FDI and economic growth and introduce more explainable variables into the growth model with the view to exactly analyzing the contribution FDI makes to economic expansion for host countries. Balasubramanyam et al.(1996) note that openness to trade is essential for growth effects of foreign investment. Borensztein et al.(1998)find that countries need a particular educational attainment level to benefit from FDI. Hermes and Lensink(2003),Durham(2004) and Alfaro et al.(2004), dealing with the relationship of regulations of financial markets, FDI and growth, find that the countries, if have better financial systems and financial market regulation, can develop full use of FDI in the more efficient manner and accomplish a higher growth rate in their national economies. Zhao et al.(2007) holds that it is the important factor why FDI exercises the negative effects on China that China lags behind in financial system and marketization. Wand and Li (2004), through a quasi endogenous growth model including FDI, conclude all the regions can be benefited from FDI spillovers only if they span the thresholds of human resources. Jiang (2008) argues that the improvement of China's economic institutes is in favor of the realization of technological spillovers from FDI and sound regime is the determinant of bringing into full play FDI's effects .Zhao(2009) maintains that China's financial market doesn't expedite the utilizing of the potential of FDI for promoting its national economic 
expansion.

The existing literature has one serious problem that economic regime is ignored in analyzing the effect of economic variables on growth. Except a few models, most researches impliedly assume that economic institutes are reasonable and proper for economic expansion. And this means that economic parties including individuals and organizations are motivated feasibly under the circumstance of governmental intervention, which can insure economy on the optimal track. But in fact, this doesn't comply with the economic practice so the existing literature's conclusions are biased and not convincing. This paper is directed at filling the blank in this regarding and its novelty is embodied by its unique perspective of regime that is referred to as the basic factor for exploring the relationship between FDI and economic growth and by the individual fixed effects model that is used to deal with the interactional laws between regime, FDI, spillovers and economic expansion. The fixed effects model includes three kinds: entity fixed effects, time fixed effects, time and entity fixed effects models. When researchers adopt the fixed effects model, most of them don't distinguish the three forms and adopt one form generally: the intercept signifies difference for each cross-section. As a matter of fact the intercept can be divided into two components: one stands for $\delta$ indicating the common effects on all the cross-sections and the other one is $\lambda_{i}$ representing the effect that is subject to a certain cross-section $i(i=1,2,3, \ldots, 23)$. We are aware of this point fully and employ the more accurate model for research so that our results are more scientific and objective. Against this backdrop, we will introduce regime as one explainable variable into the production function and use the entity fixed effects model, based on the panel data of 23 developing countries(China, India, Indonesia, Malaysia, Philippine, Thailand, Turkey, Poland, ,Russia, Czech, Slovakia, Slovenia, Hungary, Romania, Argentina, Brazil, Chili, Columbia, Mexico, Venezuela, Egypt, Morocco and South Africa), which attract the most foreign direct capital from 1999 to 2006, through the analysis of covariance estimation (ANCOVA), to probe into the law of FDI, technological spillovers and economic growth in linkage.

This paper proceeds as follows. Section 2 depicts the theories regarding institutes, FDI and economic growth. Section 3 explores the specification of econometric model, data and the results of econometric analysis. Finally section 4 will provide the main concluding remarks and concludes with policy suggestions.

\section{Literature Review on Regime of FDI and economic growth}

\subsection{Regime and economic growth}

The effect of regime on economic growth is obvious. In certain sense, just as technological progress, institutes can promote production efficiency and achieve the higher ratio of output to input. Advanced technology is the resource of economic expansion but it is just one prerequisite instead of the sufficient condition. In order to put into practice technology efficiently and extensively, there must be the adjustment in regime and idea for the sake of correctly utilizing innovative knowledge to promote economic growth. Institutes can motivate economic individuals and organizations. Technological innovation is just one kind of human being's occasional activity whose function in stimulating and driving economy may be partial and not continuous. What makes those random points form line segments and those segments be connected into lines? It is none other than institutes, which make human being's technological innovation become an unbroken activity. Firstly, institutes have the deep linkage with capital, labor forces and technology. Regimes can harmonize capital inputs and their direction. And so appropriate systems can bring into full play capital-owners and users so as to accelerate capital circulation and regeneration and prompt speed of economic running. Next, institutes have a profound effect on individuals and groups in production activities. Systems can harmonize interpersonal relationships, intergroup relationships and the relationships between individuals and groups. Appropriate regimes that are in line with economic development can steer laborers into cooperation and division of labor in each domain. Third, institutes function as a driving force of technological progress. Technology, as a single production element, has been emphasized and its high development speed is attributed to institutes basically. Particularly, the system of intellectual proper rights protects equity of knowledge product owners, consequently motivating people to make innovation in technology and quicken the technological stride. Finally, institutes take on knowledge property, which pick up the efficiency in output. Meanwhile, systems can be considered as one sort of knowledge. In this stance, the corporation's regulations can be looked upon as a strip of management knowledge which directly influences the development of business of all kinds.

\subsection{Regime and FDI}

A large number of documents have explained why multinational corporations make investment abroad rather than in their own countries. Hymer thinks that market imperfection is the ultimate condition for overseas investment and the enterprise's monopoly advantage is the determinant for its making investment abroad. R.Vermon argues that the enterprise's overseas investment is subject to the different stages in product life cycle, the product's comparative advantage and competitive conditions. The internalization theory maintains that foreign investment is attributed to market imperfection such as market failure, which may induce the rising transaction costs in the enterprise, and the enterprise organizes its internal transactions by this form of organization-"enterprise" so as to reduce the transaction 
costs for the purpose of maximizing earnings. Kojima is of the opinion that it is the comparative advantage for multinational corporations to invest abroad.

Dunning argues that three determinants of multinational corporations making foreign direct investment are ownership advantage, internalization advantage and location advantage. Policies and institutes in host countries are playing a more important role in location and internalization advantages (victor, Jeffrey and Bistra, 1988).Dunning points out (1998) that the location theory is being featured by the new trends: firstly, multinational corporations are inclining to move into those countries and regions for direct investment which have sounded legal systems, attach great importance to the protection of intellectual property rights, are abundant in supply of intellectual resources and high qualification talents; secondly, they choose those places to make investment which can strengthen or supplement their core competitiveness; Finally, the determinants of FDI in location are comprehensive. According to Narula and Dunning, the host country's institutes, as an important component of creative assets, are becoming increasingly significant in attracting and utilizing FDI to serve national economy.

Regime is increasingly emphasized in attracting FDI inflows as foreign investors must adapt their commercial strategies into the host country's institutes (Oxley, 1999, Peng 2000). Otherwise their enterprises can't be put in operation smoothly and their interests will be not realized because of the conflict with the host country in objective. More researches have been proving that the goals of multinational corporations are to expand their resources and upgrade their ability through exercising effect on the regions where they make investment as well as utilizing these nations' resources. Therefore, the more favorable the regime in the host country is in increasing resources and capability for FDI, the more attractive the country will be to it. Institutes with bad quality may contribute to the rising costs for transactions, negotiations and executions (Antal, 1998), which suggests that FDI must bear higher transaction costs when establishing new enterprises in the nation, and meanwhile hampers potential trade (Meyer, 2001).Globerrman and Shapiro(2002) hold that the same factors have the impact on FDI inflows or outflows. Levchenko(2004) argues that the gap in institute is the origin of comparative advantages and some sectors are regime-denser than others so as to create more business opportunities. Alfaro al et.(2005) think that bad institutes can explain why poor countries attract a small quantity of FDI and Fan et al.(2009) maintain that the deficiency in China's system may provoke that it can't have more FDI.

Regime, being one crucial aspect regarding location advantage in the host country, has an impact on the location choice for foreign direct investment and is playing a more important and obvious role in attracting FDI than natural resources. Therefore, we maintain that FDI is one potential element to drive the economic growth and turning its potential into reality needs a proper institute arrangement. In the absence of high quality institutes, FDI may give rise to the negative result, even blocks economic expansion and this may be of assistance to investment return for the multinational corporation but not in favor of the host country's welfare. Forasmuch, the good institutes in the host country is vital to fully effect the potential from FDI as well as attracting FDI.

\section{Models and Empirical Analysis}

\subsection{Production Function, Data Origins and Panel Data Models}

\subsubsection{Production Function and Data Origins}

According to the above analysis, we introduce the institute into the production function as well as investment made up of domestic and foreign capital. In addition, in terms of economic theories, growth also depends on infrastructure and stability in economic environment. So, we define the production function as follows:

$$
F_{i t}=F\left(G C F_{i t}, F D I_{i t}, R E G I_{i t}, C T R L_{i t}\right)
$$

Suppose the equation is linear, we construct the following empirical model by replacing $F_{i t}$ with $O U T P U T_{i t}$ :

$$
F_{i t}=c_{0}+c_{1} G C F_{i t}+c_{2} F D I_{i t}+c_{3} R E G I+\sum_{j=4} c C T R L_{i j t}+\mu_{i t}
$$

OUTPUT is the independent variable, denoting economic growth, proxied by GDPPC, originated from UNCTAD; GCF is gross capital formation representing domestic investment, originated from UNCTAD ; FDI is foreign direct investment, proxied by its real stocks, originated from UNCTAD; REGI symbolizes institute, proxied by freedom index abstracted from Frazer Data; CRTR is other explainable variables, including labor, stability of economic climate and infrastructure level; $i(i-1,2,3 \ldots, 23)$ and $t(t=1999, \ldots 2006)$ stand for the $i$ th country and the $t$ th year; $\mu$ is the residual term. Labor is proxied by primary enroll rate (EPG), second enroll rate (ESG) and tertiary enroll rate (ETG), all originated from the world bank, the stability in economic environment is proxied by inflation (INFL), from the world bank, infrastructure is proxied by the number of people having fixed and mobile phones in per 100 persons (FMP), from the world bank. The interaction term of regime and FDI (FDISTOCKREGI) is equal to freedom index multiplying FDI stock. All the data are processed by normalization for tackling the difference in dimension, then time 10 to obtain the 
final data which are used through E-views 5.1 to make the estimation of the model.

\subsubsection{Classification of panel (time series /cross section) data model}

In terms of difference in slope coefficients and intercepts, the panel data model is divided into three kinds. The first one is postulated as: $y_{i}=\alpha+x_{i} \beta+\mu_{i}, i=1,2, \ldots, N$

Which means both slope and intercept coefficients are the same, implying there is neither effect from individuals nor structure difference; The second is the variable intercept model: $y_{i}=\alpha_{i}+x_{i} \beta+\mu_{i}, i=1,2 \ldots N$

where regression intercepts are the same, and slope coefficients are not. The last model is the variable coefficient one: $y_{i}=\alpha_{i}+x_{i} \beta_{i}+\mu_{i,} \quad i=1,2 \ldots N$

Where neither regression slope coefficients nor intercepts are identical, implying that the difference exists in the effect from cross sections and the structure is variable among the entities.

The variable intercept model is the most widely used of all the panel data models, in which the effects from the individuals are considered, embodied by intercepts. Attributable to the different modes of individual effects, it is classified into 3 types: entity fixed effects regression model (EFERM), time fixed effects regression model time entity fixed effects regression model. In this paper we will adopt the first type so we just describe it. From the perfectives of time and entity, variables in panel data regression models have the same marginal impact on independent one and other variables' influencing on the independent variable is subject to individuals rather than time as well as the model's explainable variables. Under this circumstance, the model should be established as EFERM:

$y_{i t}=\delta+\lambda_{i}+\sum_{k}^{K} \beta_{k} x_{k i t}+\mu_{i t}$

\subsection{Testing models}

We first test what model the sampling data are suitable for. If they fit panel data models, we then test which models are more appropriate, fixed or random effects. If fixed effects models are better, we test which fixed ones are the most proper of the 3 types. In testing whether the fixed model is used or not, we don't employ Hauseman method, for it can test the validity of fixed model but can't judge exactly what kind of fixed model is suitable. We use the covariance analysis (aforesaid) to make the test of related models, results being presented on table 1 and all critical values calculated through SPSS. In the following tables, symbols of $*, * *$ and $* * *$ denotes the significance at the level of $1 \%$, $5 \%$ and $10 \%$ respectively.

Specifically, we define the flowing statistics for model testing:

$$
\begin{gathered}
F_{1}=\frac{\left(S_{2}-S_{1}\right) /[(N-1) k]}{S_{1} /[N T-N(k+1)]} \sim F[(N-1) k, N(T-k-1)] \\
F_{2}=\frac{\left(S_{3}-S_{1}\right) /[(N-1)(k+1)]}{S_{1} /[N T-N(k+1)]} \sim F[(N-1)(k+1), N(T-k-1)] \\
F=\frac{(R R S S-U R S S) /(N-1)}{U R S S /(N T-N-K+1)} \sim F(N-1, N(T-1)-K+1)
\end{gathered}
$$

Where $\mathrm{N}$ is the number of sections, $\mathrm{T}$ the time length and $\mathrm{k}$ the number of independent variables. In addition, RRSS is the restricted residual sum of squares for equation (6) (pooled regression model) and URSS is the unrestricted residual sum of squares for equation (6).It can be seen from the table 1 that because F2 in model 1 is more than its critical value and $\mathrm{F} 1$ less than its critical value at the significant level of 5\%, showing the model rejects hypothesis $\mathrm{H} 2$ but doesn't reject $H_{1}: \beta_{1}=\beta_{2}=\ldots=\beta_{N} ; H_{2}: \alpha_{1}=\alpha_{2}=\ldots=\alpha_{N} \quad \beta_{1}=\beta_{2}=\ldots=\beta_{N}$, the model the fits varying intercept one .Likewise, models 2 and 3 both at the significant level of $10 \%$, models 4 and 5 both at $1 \%$, all reject hypothesis $\mathrm{H} 2$ but don't reject $\mathrm{H} 1$, these models fits the varying intercept one. To sum up, 5 selected models all are suitable for variable intercept ones (equation 4) at low levels.

$\mathrm{F}$ in all models is more than the critical value, resulting in the conclusion of rejecting the null assumption. Hence, it is reasonable and proper to adopt the entity fixed effects model, equation 6. The results are estimated through E-views 5.1, being showed on the table 2. Since individual cross-sections are different in heteroscedasticity, estimation results by LSDV are biased. So we adopt GLSDV for making the estimation of parameters and the residual variance is used as the weight to smooth away the problem of heteroscedasticity of cross sections. The empirical estimations are showed on the table 6 where $*, * *$ and $* * *$ denote the significant level of $1 \%, 5 \%$ and $10 \%, \mathrm{t}$ value is in parentheses.

It is noting that we proxy regime value at time $\mathrm{t}-1$ for $\mathrm{t}$ and $\mathrm{ETG}$ value at time $\mathrm{t}-1$ for $\mathrm{t}$ for estimation because of time 
lagging. There are 5 models which have different explainable variables. $\mathrm{F}$ in all the models exceeds the critical value, suggesting that models pass the examination of significance, adjusted $R^{2}$ more than 0.99 means good the degree of fitting of models, $t$ value exceeding its critical value implies coefficients for explainable variables are significant at the low level. Hence, models and explainable variables are powerful and persuasive to account for the economic issues. The sums of constants for cross sections, which mean the effects from unobserved elements or the elements except explainable variables, are all in 5 models respectively close to 0 or equal to 0 .

Covariance matrix reflects the volatility of two variables. Positive covariance indicates two variables have the same direction in change and minus covariance means the different direction. Covariance, if being 0 , hints the independence of two variables. The numbers on and outside the diagonal line in the coefficient covariance matrixes, which is not shown because of the limited page, are all extremely small, almost close to 0 , respectively hinting no autocorrelation of each variable and no collinearity and dependence among variables. This satisfies the requirement of strict exgoeneity so covariance analysis is consistent and the estimated results are of high convincing. However, owe to limited pages, we didn't list the covariance matrix of models.

In order to test robustness of our findings, we add one explainable variable of rule to every model (see the table 3 ). The results show that adjusted $R^{2}$ is more than 0.99 , suggesting that models are significant and still of a good fit, $t$ value for each variable is significant at the low level. More important, the coefficient of each variable in all the models is small in change, compared with the original ones, and this infers that our findings are vey robust. It is worth noting that the value for rule at time $t$ is proxied by at time $t-1$ because of time lag in model 5 .

In tables 2,3,4 and 5 numbers in small brackets are value $t$, donating whether the variable is significant or not. The coefficients of FMP in model 1, 2, 3 and 4 are 0.1, 0.06, 0.13 and 0.06(table 2), suggesting good infrastructure has the positive effect on economic growth. The coefficients for INFL are minus, indicating that volatility in economy influences economic expansion negatively. Labor with tertiary education makes the greater contribution than second and primary school education because the former coefficients are $0.07,0.09$ and 0.1 in model 2, 4, and 5 but the two latter coefficients are both just 0.03 . This indicates that the higher labor is, the more powerful it will promote economic progress.

The coefficients for FCF in models $1,2,3,4$ and 5 are $0.76,0.78,0.77,0.78$ and 0.83 respectively and are significant at the low level, which are much larger than any other variables, suggesting that domestic investment exercises the positive effect on economic expansion powerfully and makes the greatest contribution to economy of all variables. So, economic growth in selected developing countries depends on mainly domestic investment. The coefficients for FDI in models $1,2,3$ and 5 are $0.11,0.8,0.1$ and 0.08 and are significant at the low level, which means that foreign investment imposes economy positively but not strongly. The coefficients for regime in models 1,23 and 5 are $0.07,0.07,0.05$ and 0.05 respectively, showing that regime influences economy positively but more weakly than domestic and foreign domestic.

It is worth noting the coefficient for the interaction term of regime and FDI is 0.114 . That is larger than regime and FDI, meaning that their mutual action makes the greater contribution to GDPPPC positively than individual regime or FDI. Hence, it is under the good institutes that FDI can further promote economic growth. The high quality in regime is the sufficient condition for FDI to be fully utilized for well serving economic performance in the host developing countries.

It is understood that the coefficients for variables from regression describe the common information for individuals and differences among chosen cross sections exist, whose information is reflected by the constant for each cross section Furthermore, the constant of each section describes the effect on economy of unobserved variables or the variables not included in the models, which is subject to individuals rather than time. Therefore, the cross section's constant embodies the effect of individual entity difference variables on growth, such as the host country's economic volatility, political regime, economic structure, technological level, management style, demographic feature and entrepreneur group. We average the constants for each country in 5 models, the table of which is not provided because of the limited page, so as to find out that in 3 African countries, 3 eastern European countries in 6, China, India and Turkey the individual difference variables have the positive effect on economy but in 4 Latin American countries in 6, 3 southeast Asian countries in 4 (excluded China), Russia, Czech Republic and Slovakia they have the negative effect.

Compared with Egypt (2.57325) and India (0.367561), China has the smaller constant for individual difference variable of 0.160153 , meaning China is not satisfactory in many aspects concerning economic development and potential such as its industrial structure, democracy, fairness and legal system. As a matter of fact, existing factors in China, for instance unsounded economic institutes, have been placing the restriction on economic growth somewhat.

\subsection{Regime, FDI and domestic investment}

Domestic investment makes the greatest contribution to economic growth so we determine to explore the effect of regime and FDI on domestic investment for further finding out the law regarding their linkage. For this purpose, we adopt the following model arising from UNCTAD(1999) 


$$
G C F_{t}=\alpha+\beta_{1} F_{t}+\beta_{2} G_{t}+\varepsilon_{t}
$$

$G C F_{t}$ denotes domestic investment, $F_{t}$ presents $\mathrm{FDI}_{t}, G_{t}$ is output and $\varepsilon_{t}$ is random error. For embodying regime's effect on domestic investment, we add variables, institute and the interaction of institute and FDI. Replacing $F_{t}$ and $G_{t}$ with values of FDISTOCK and GDPPC, we obtain the following model:

$$
G C F_{i t}=\alpha+\beta_{1} \text { DDPPC }_{\mathrm{it}}+\beta_{2} \text { REGI }_{i t}+\beta_{3} \text { FDISTOCK }_{i t}+\beta_{4} \text { FDISTOCKREGI }_{i t}+\varepsilon_{i t}
$$

Considering time lag of regime, we proxy its value at time $t$ with $t-1$.Regression results are shown on table 4 .

Then we deal with the effect of regime on FDI. Based on UNCTAD, the determinants of FDI are classified into two kinds: traditional factors in which the market size of the host country is the most important and non-traditional ones. With the economic growing in developing countries at the high speed, non-traditional elements play an increasingly important role in attracting FDI inflows, such as openness, governmental interventions and economic institutes, mainly because multinational corporations seek for long-term interests and attach great importance to the regime environment of affecting economic efficiency. Therefore,, we use GDPPC, FMP (infrastructure) and REGI (institute) as explanatory variables and FDI as the independent one, hypothesizing linearity existing, to define the following regression equation:

$$
F D I_{i t}=c+c_{1} G D P P C_{i t}+F M P_{i t}+R E G I_{i t}+\mu_{i t}
$$

FDISTOCK is the proxy for FDI and $\mu_{i t}$ is the error correction term. Owe to time lag, we use the value for GDPPC at time $\mathrm{t}-1$ to proxy $\mathrm{t}$ for estimations (see table 5).

Table 4 reveals that GDPPC has the biggest effect on domestic investment with the coefficient being 0.79 , domestic regime has the smallest effect with coefficient being -0.05 , the interaction term of regime and FDI are more powerful in influencing domestic investment than FDI, the coefficients being 0.18 and 0.08 respectively. Obviously the interaction of regime and FDI has the much greater effect on domestic investment than FDI and this suggests that it is under the good institutes that FDI can crowd in domestic capital. Besides, in terms of table 11, regime has the positive crowed-in effect on FDI, with the coefficient being 0.11 .

To sum up, regime promotes economic growth for host countries (see table 6): first, it positively affects economic expansion directly; then, it indirectly drives economic growth through pulling FDI into host countries; finally, coupled with regime, FDI crowds in domestic investment to bolster economy for host nations and this has the greatest effect on economic increasing with direct and indirect effect indexes being 1.83 and 2.34 respectively.

With regard to FDI, it co-functions on economic growth together with regime in the direct manner (interaction of FDI and regime). What is more, it imposes the indirect effect on economy by crowding in domestic investment. Therefore, the institutes with high quality in host developing countries are the prerequisite of achieving the technological spillover effects from FDI. Whether the potential of FDI is fully developed to serve the host country's economy well depends on the quality of the host country's regime.

\subsection{FDI's positive effect on developing host countries is not fully materialized from regime}

The coefficients for the regime variable in Models 1, 2, 3 and 5 are equal to $0.07,0.07,0.05$ and 0.05 correspondingly, showing that regime has the positive effect on economic growth but very marginally. Besides, it negatively influences domestic investment. Hence, the regime variable's effect on growth is not significant. From the historic point of view, this is mainly due to the validity and inefficiency in institute structures with the shortage of pricing mechanism. After World War 2, developing countries adopted the "large and public" model of property rights under the influence of the Stalinist mode, featured by high centralization at the dominant position in resources allocation and ignoring the market's function, as the result that validity in allocation of social resources and the efficiency of regime can't be guaranteed. The shortage of private ownership contributed to the shortage of the driving force for innovation. Under the circumstance of property rights being not protected, it is a rational choice for individuals to avoid the risk of innovation. Thus, a variety of economic factors can not play their desired effects and economy is in a state of low growth, even stagnation. So, regime in developing countries has been in a non-equilibrium state for long time and the supply in regime can't meet the demand, causing a small net income, even to 0 , far away from attaining the "Pareto optimal".

In order to shake off stagnation of regime and to achieve the realization of "Pareto optimal", developing nations adopt the strategy of attracting FDI and regard it as an effective way to speed up economic liberation, marketization and privatization process. Take China as one example. Since 1978 China has rolled the ball of making economic system reform and regarded the utilization of FDI as the catalyst to serve economic development. In 1979 she established 4 special economic zones such as Shenzhen, opened up 14 coastal cities in 1985, opened up northern coastal areas in 1988, opened up Pudong in 1990 and decided to further expand the scope of opening up to the outside world in 1992 so as to accomplish such an opening- up pattern as "opening up along coasts, rivers and boarders" "opening up from coasts to 
inlands" and "opening up from the south to the north". In 1997 China drafted and promulgated legal documents to encourage FDI to invest in central and west regions. FDI inflows into China have been surging high. Up to 2006, it has been for 14 years to be ranked No. 1 in attracting FDI in all the developing countries. So, China's 30 years process of economic development and reform is the process of FDI inflowing, which is also the process of breaking the traditional monopoly of state-owned economy. Essentially it is a process of China's economic institute transformation.

However, because of the old system's inertia and the new system's time lag, the FDI's effect on economic growth has not been brought into full play, which is reflected by small variable coefficients in the above regression models. From economics, these developing countries are being at the economic transitional stage, featured by dual economic regimes, the market system being intertwined with the traditional one, and the larger degree in market distortion. Hence, the element structure is not reflected through the market information, the difference of which the policy guidance in host countries doesn't reflect. Under such circumstances, the developing countries have conflict with multinational corporations in economic dominance and market resources, which is not conducive to building competitive advantages for host nations during the process of using FDI so its positive effect on economic growth is very marginal.

\section{Concluding remarks and policy suggestions}

The paper, built on the panel data of 23 developing host countries that attract the most FDI, through the individual fixed effects regression model and covariance analysis of GLS to deal with the correlation of FDI and economic growth. The above research shows that regime and FDI both have the direct and weak effect on economic expansion. However, their interaction term has the positive effect on growth significantly in both the direct and the indirect manners. In case of FDI, the channels to support economic growth are interacting with regime to advance economy and at the same time crowding in domestic capital to drive economy. Hence, a good institute can ensure technological spillovers from FDI. Further, whether FDI's potential for expansion is fully developed, whether FDI's spillovers are materialized in economic practice and to what extent FDI's positive externalities are realized to serve economy depend on the institute quality. Therefore, efficient institutional arrangements are the ultimate cause for achieving FDI's spillover effects to promote economic growth for developing host countries. In addition, we find that the regimes of developing nations don't make the big contribution to economic development, the coefficients being 0.07 or 0.05 and have the negative effect on domestic investment for the coefficient being -0.05.It is implied that the defects in regime of developing economies is the critical reason why FDI doesn't bring into expected play in the development of their national economy and this can explain why developing nations implement the preferential policies to inspire and motivate foreign capital into their markets to start business in different forms. The existence of preferential policies implies the defects of regime and market distortion in developing countries, meaning that economic resources such as fund resources are not allocated as per market rules. Existing literature and experience prove that preference plays the limited role in location choice of FDI. Only Under the condition of the involvement of other production elements can policies in favor of FDI matter much economically. Hence, developing economies should highlight a package of operational resources (including technology, knowledge, expertise, market opportunities and business model) to be introduced into their markets through FDI inflows for the sake of maximizing the realization of spillover effects and enhance endogeneity for national economy. To this end, the host countries need to make the innovation in economic regime, strengthen the reform for property rights, and actualize taking-in and utilizing of technologies arising from FDI through the market mechanism. Further, the developing countries should strengthen the reform in political institutes. Olsen's proposal of establishing of market-augmenting government is worth learning and putting into practice. Developing countries can draw on this as the reference, experience and guideline for making political reform.

\section{References}

Douglas C North. (2003). Empirical studies of changes in institution. Beijing: Economic Science Press.

Gao, Tiemei .(2006). Econometric analysis and Modeling. Beijing: Tsinghua University Press.

John Robertson. Budge Lin. (2008.). Econometric panel data analysis. Tianjin: Nankai University Press.

Luo, Biliang. (2005) .New Institutional Economics. Taiyuan: Shanxi Economic Press.

Matthias Musse. Jose Luis Groizard. (2008) Foreign Direct Investment, Regulations and Growth. The world Economy. PP.861-886.

Nicole Madariaga and Sandra Poncet. (2007). FDI in Chinese cities: spillovers and Impact on growth. The World Economy .PP837-861.

Philippe Aghion. (2004).Endogenous growth theory . Beijing; Beijing University Press.

Shen, Guilong. (2007) On performance of FDI in China. Shanghai: Shanghai people publisher.

Tommy. (2008) .With economies in transition, foreign direct investment and technology spillover effects. Economic Research . PP26-38. 
Wang, Zhi-peng and Li, zinai. (2004) Foreign direct investment, spillovers and endogenous economic growth. Wenhui world economy. PP23-23.

Yu, Junnian. (2006). Econometric software (Eviews use). Beijing: Foreign Trade and Economic University Press.

Zhang ,Cheng Zhao. (2006) Financial deepening, economic growth, FDI spillover effects and regional economic growth. The number of economic and technical economic studies .PP74-82.

Table 1.Testing models

\begin{tabular}{|c|c|c|c|c|c|}
\hline & Model 1 & Model 2 & Model 3 & Model 4 & Model 5 \\
\hline Independent variable & GDPPC & GDPPC & GDPPC & GDPPC & $G D P P C$ \\
\hline Explainable variable & $\begin{array}{l}\text { GCF } \\
\text { FDISTOCK REGI } \\
\text { INFL } \\
\text { FMP } \\
\text { ESG }\end{array}$ & $\begin{array}{l}\text { GCF } \\
\text { FDISTOCK REGI } \\
\text { INFL } \\
\text { FMP } \\
\text { ETG }\end{array}$ & $\begin{array}{l}\text { GCF } \\
\text { FDISTOCKREGI } \\
\text { INFL } \\
\text { FMP } \\
\text { EPG }\end{array}$ & $\begin{array}{l}\text { GCF } \\
\text { FDISTOCKREGI } \\
\text { INFL } \\
\text { FMP } \\
\text { ETG }\end{array}$ & $\begin{array}{l}G C F \\
\text { FDISTOCK REGI } \\
\text { ETG }\end{array}$ \\
\hline S1 & 16.73751 & 20.86029 & 12.77012 & 33.25165 & 60.25082 \\
\hline $\mathrm{S} 2$ & 151.1038 & 151.8433 & 149.2115 & 156.7099 & 157.9668 \\
\hline S3 & 251.3582 & 257.7802 & 257.2774 & 265.8306 & 267.9779 \\
\hline RRSS & 130.6963 & 132.3283 & 128.9412 & 147.0247 & 142.8310 \\
\hline URSS & 16.737508 & 20.8602878 & 12.8775253 & 33.25165 & 60.250821 \\
\hline Critical value for F1 & $\begin{array}{l}1.58 * * * \\
1.81 * * \\
2.35 *\end{array}$ & $\begin{array}{l}1.58 * * * \\
1.81 * * \\
2.35 * \\
\end{array}$ & $\begin{array}{l}1.58 * * * \\
1.81 * * \\
2.35 *\end{array}$ & $\begin{array}{l}1.40 * * * \\
1.54 * * \\
1.85 *\end{array}$ & $\begin{array}{l}1.35 * * * \\
1.46^{* *} \\
1.72 *\end{array}$ \\
\hline Critical value for F2 & $\begin{array}{l}1.58 * * * \\
1.80 * * \\
2.33 * \\
\end{array}$ & $\begin{array}{l}1.58 * * * \\
1.80 * * \\
2.33 *\end{array}$ & $\begin{array}{l}1.58 * * * \\
1.80 * * \\
2.33 *\end{array}$ & $\begin{array}{l}1.39 * * * \\
1.53 * * \\
1.83 *\end{array}$ & $\begin{array}{l}1.33 * * * \\
1.44 * * \\
1.69 *\end{array}$ \\
\hline Critical value for $\mathrm{F}$ & $\begin{array}{l}1.45 * * * \\
1.61 * * \\
1.95 *\end{array}$ & $\begin{array}{l}1.45 * * * \\
1.61 * * \\
1.95 *\end{array}$ & $\begin{array}{l}1.45 * * * \\
1.61 * * \\
1.95 *\end{array}$ & $\begin{array}{l}1.45 * * * \\
1.61 * * \\
1.95 *\end{array}$ & $\begin{array}{l}1.45 * * * \\
1.61 * * \\
1.95 *\end{array}$ \\
\hline F1 & 1.398793 & 1.094079 & 1.86168 & 1.552645 & 1.271654 \\
\hline F2 & 2.093546 & 1.696244 & 2.859591 & 2.43748 & 2.162652 \\
\hline $\mathrm{F}$ & 48.27908 & 37.89063 & 63.90956 & 24.41761 & 9.843448 \\
\hline
\end{tabular}

The residual sums of square for Equations (5), (4) and (3) are $s_{1}, s_{2}$ and $s_{3}$ respectively.

Table2. Estimation Results

\begin{tabular}{|c|c|c|c|c|c|}
\hline Variable & Model 1 & Model 2 & Model 3 & 4Model 4 & Model 5 \\
\hline $\mathrm{C}$ & $\begin{array}{l}-0.307644 * * \\
(-2.506964)\end{array}$ & $\begin{array}{l}-0.3244327^{*} \\
(-2.987131)\end{array}$ & $\begin{array}{l}-0.419256^{*} \\
(-3.460977)\end{array}$ & $\begin{array}{l}-0.201262^{* *} \\
(-2.349241)\end{array}$ & $\begin{array}{l}-0.487822 \\
(-6.732819)\end{array}$ \\
\hline GCF & $\begin{array}{l}0.761088^{*} \\
(21.30281)\end{array}$ & $\begin{array}{l}0.784022 \\
(22.24051)\end{array}$ & $\begin{array}{l}0.769801 \\
(21.59747)\end{array}$ & $\begin{array}{l}0.782645 \\
(21.84777)\end{array}$ & $\begin{array}{l}0.834254 \\
(23.03530)\end{array}$ \\
\hline FDISTOCK & $\begin{array}{l}0.108174^{*} \\
(2.819797) \\
\end{array}$ & $\begin{array}{l}0.076587 * * \\
(2.006221) \\
\end{array}$ & $\begin{array}{l}0.099182 * * \\
(2.600336) \\
\end{array}$ & & $\begin{array}{l}0.079213 * * \\
(2.113416) \\
\end{array}$ \\
\hline REGI & $\begin{array}{l}0.066593 * \\
(5.021493)\end{array}$ & $\begin{array}{l}0.068197 \\
(6.303747)\end{array}$ & $\begin{array}{l}0.053968 \\
(4.236976)\end{array}$ & & $\begin{array}{l}0.053154 \\
(4.491910)\end{array}$ \\
\hline INFL & $\begin{array}{l}-0.061101^{*} \\
(-4.795396)\end{array}$ & $\begin{array}{l}-0.046150^{*} \\
(-3.950121)\end{array}$ & $\begin{array}{l}-0.061010 \\
(-4.836375) \\
\end{array}$ & $\begin{array}{l}-0.044302 \\
(-4.381320)\end{array}$ & \\
\hline FMP & $\begin{array}{l}0.096854^{* * *} \\
(2.774869) \\
\end{array}$ & $\begin{array}{l}0.062617^{* *} \\
(2.109830)\end{array}$ & $\begin{array}{l}0.128475^{*} \\
(3.910108) \\
\end{array}$ & $\begin{array}{l}0.058398^{* *} \\
(2.015560) \\
\end{array}$ & \\
\hline ETG & & $\begin{array}{l}0.070561^{*} \\
(3.503840)\end{array}$ & & $\begin{array}{l}0.086044^{* *} \\
(3.258525) \\
\end{array}$ & $\begin{array}{l}0.098581 \\
(4.373623) \\
\end{array}$ \\
\hline ESG & $\begin{array}{l}0.026814 * * * \\
(1.772594)\end{array}$ & & & & \\
\hline EPG & & & $\begin{array}{l}0.031216^{* * *} \\
(2.815023) \\
\end{array}$ & & \\
\hline FDISTOKREGI & & & & $\begin{array}{l}0.113841 * * \\
(3.347033)\end{array}$ & \\
\hline \multicolumn{6}{|l|}{ REGULATION } \\
\hline & 0.990521 & 0.994306 & 0.989215 & 0.993409 & 0.990828 \\
\hline F & 598.1248 & 998.7664 & 525.1189 & 894.1807 & 665.7535 \\
\hline $\mathrm{D}-\mathrm{W}$ & 1.696135 & 1.832317 & 1.775156 & 1.653562 & 1.845642 \\
\hline
\end{tabular}


Table 3. Checking robustness of models

\begin{tabular}{|c|c|c|c|c|c|}
\hline Variable & Model 1 & Model 2 & Model 3 & 4Model 4 & Model 5 \\
\hline $\mathrm{C}$ & $\begin{array}{l}-0.464449 * \\
(-3.658992)\end{array}$ & $-0.388850 *(-3.433268)$ & $-0.530774(-4.246675)$ & $\begin{array}{l}-0.290063^{*} \\
(-3.096830) \\
\end{array}$ & $\begin{array}{l}-0.552743 \\
(-7.530155)\end{array}$ \\
\hline GCF & $\begin{array}{l}0.716546 \\
(18.35161) \\
\end{array}$ & $\begin{array}{l}0.728858 \\
(18.99615)\end{array}$ & $0.742130(19.58209)$ & $\begin{array}{l}0.744960 \\
(20.39520)\end{array}$ & $\begin{array}{l}0.831518 \\
(22.20232)\end{array}$ \\
\hline FDISTOCK & $\begin{array}{l}0.098862 * * * \\
(2.586100)\end{array}$ & $0.073968 * * *(1.896635)$ & $0.087829 * *(2.323276)$ & & $\begin{array}{l}0.078415^{* *} \\
(2.043411)\end{array}$ \\
\hline REGI & $\begin{array}{l}0.046976^{*} \\
(3.208969)\end{array}$ & $\begin{array}{l}0.046144 * * * \\
(3.437092)\end{array}$ & $0.044285 *(3.155535)$ & & $\begin{array}{l}0.036939 * \\
(3.176719)\end{array}$ \\
\hline INFL & $\begin{array}{l}-0.062349 \\
(-4.471802)\end{array}$ & $-0.051226^{*}(-3.995798)$ & $-0.060645(-4.735776)$ & $\begin{array}{l}-0.048960 \\
(-4.605796)\end{array}$ & \\
\hline FMP & $\begin{array}{l}0.147471 * \\
(3.943896) \\
\end{array}$ & $0.113424 * *(3.068475)$ & $0.162265(4.773442)$ & $\begin{array}{l}0.101918^{*} \\
(3.108184) \\
\end{array}$ & \\
\hline ETG & & $0.076100 * * *(2.735219)$ & & $\begin{array}{l}0.081013 * \\
(2.935841)\end{array}$ & $\begin{array}{l}0.097561 \\
(4.456348)\end{array}$ \\
\hline ESG & $\begin{array}{l}0.032757 * * * \\
(1.912237)\end{array}$ & & & & \\
\hline EPG & & & $0.031116^{* * *}(2.750235)$ & & \\
\hline FDISTOKREGI & & & & $\begin{array}{l}0.087832 * * \\
(2.575415) \\
\end{array}$ & \\
\hline REGULA & $\begin{array}{l}0.045898 * * * \\
(2.624322)\end{array}$ & $\begin{array}{l}0.036811 \\
(2.361247)\end{array}$ & $\begin{array}{l}0.036008 * * \\
(2.282934)\end{array}$ & $\begin{array}{l}0.042882 \\
(2.964797)\end{array}$ & $\begin{array}{l}0.044078^{*} \\
(3.322721)\end{array}$ \\
\hline $\mathrm{R}_{\mathrm{ad}}{ }^{2}$ & 0.987753 & 0.987723 & 0.987195 & 0.992528 & 0.991903 \\
\hline $\mathrm{F}$ & 364.3321 & 444.8931 & 426.3539 & 760.0614 & 726.9496 \\
\hline $\mathrm{D}-\mathrm{W}$ & 1.663764 & 1.705245 & 1.741149 & 1.737913 & 1.780480 \\
\hline
\end{tabular}

Table 4. Effect of FDI and regime on domestic regime

\begin{tabular}{|c|c|c|c|c|c|c|c|}
\hline & $\mathrm{C}$ & GDPPC & REGI & FDISTOCK & FDISTOCKREGI & $\mathrm{R}_{\mathrm{ad}}{ }^{2}$ & D.W. \\
\hline GCF & $\begin{array}{l}0.348186 \\
(5.207076)\end{array}$ & $\begin{array}{l}0.787834 \\
(22.13596)\end{array}$ & $\begin{array}{l}-0.050893 * \\
(-3.749940)\end{array}$ & $\begin{array}{l}0.077325 * * \\
(2.282046)\end{array}$ & $\begin{array}{l}0.177032 \\
(4.400974)\end{array}$ & 0.983414 & 1.905659 \\
\hline
\end{tabular}

Table 5. Regime's effect on FDI

\begin{tabular}{|l|l|l|l|l|l|l|}
\hline & C & GDPPC & REGI & FMP & $\mathrm{R}_{\mathrm{ad}}{ }^{2}$ & D.W. \\
\hline FDISTOCK & $0.657615^{*}$ & 0.404924 & 0.106755 & 0.617655 & 0.917149 & 1.665907 \\
& $(-3.822704)$ & $(6.964508)$ & $(2.688304)$ & $(12.38804)$ & & \\
\hline
\end{tabular}

Table 6. Degree of FDI and regime effects on growth and mode

\begin{tabular}{|l|l|l|l|l|l|}
\hline Variable & Mode & Coefficient & Effect index & Channel \\
\hline Regime & direct & 0.06 & 1 & Promote \\
& indirect & 0.11 & 0.17 & FDI inflows \\
\hline FDI & direct & 0.0925 & 1.54 & crowd in domestic & weak \\
& indirect & 0.08 & 1.05 & weak \\
investment & crowd in \\
\hline Interaction of regime and FDI & direct & 0.11 & 1.83 & 2.34 & modest \\
& indirect & 0.18 & strong \\
\hline
\end{tabular}

Coefficient is average of coefficients in each model. 0.06 is used as the basic point to calculate the effect index; the direct effect index multiplying the coefficient of functioned variable to yield the indirect effect one. 